\title{
Biopolitical SuRveillance in the INTERNATIONAL ARENA
}

Biopolitics and health surveillance have increasingly entrenched themselves within the international political realm. Traditionally being the realm of individual states, public health is increasingly a concern of the international community. ${ }^{1}$ The World Health Assembly (WHA) vastly increased the scope of the International Health Regulations (IHR) during its 2005 revisions. The changes greatly expanded the scope of reportable diseases, designated specific offices in each country to be available around the clock to facilitate communication between the World Health Organization (WHO) and national governments, and required each state to develop and maintain core public health capacities-including surveillance. The United States, along with other countries, has developed a national strategy for pandemic influenza, replete with preparation guidelines, contact people in each state, and public service announcements. Infectious diseases are moving from the realm of a health issue to that of a national and international security threat. These strategies can appear quite overbearing and intrusive, and may raise concerns over the nature of biopolitical citizenship.

Need such surveillance always be frightening? Increasing attention to the public's health presents numerous opportunities that allow the international community to uphold a basic human right to health. These systems can help prevent a new epidemic before it takes root, make treatment available to the sick faster, and facilitate international cooperation on addressing health concerns. The revised IHR are now more relevant to people's lives, and preparations for an influenza pandemic should allow governments to mobilize faster to protect the public. Public health now commands more attention from policymakers and more resources than in the past.

If we think about the nature of surveillance and its relationship with public health, we can see why competing views on its usefulness 
exist. Disease control campaigns frequently necessitate an extensive surveillance network. Public health officials must be able to identify cases of a particular disease, track its spread, and monitor local communities to ensure that the disease does not return. When generating support for a control campaign, advocates often claim that constructing surveillance structures will strengthen the state's public health infrastructure. Once these structures are in place, they can easily be adapted to monitor general public health concerns and bring assistance to those in need. Opponents counter that such promises are illusory at best. Local communities have resisted the state's surveillance capabilities, claiming it merely served to unnecessarily extend the state's reach into private, personal arenas. It is also unclear how well these structures have contributed to an overall strengthening of a country's public health infrastructure.

This chapter explores the potential benefits and difficulties associated with the rise of biopolitics and health surveillance. Why do communities resist this biopolitical surveillance, and what are the potential benefits of increased biopolitical surveillance? This requires demonstrating how health and health status have been used as social and political markers in international politics throughout history, explaining how biopolitics and biopolitical surveillance have changed in modern times, highlighting the concerns it raises, and identifying the potential benefits associated with increased surveillance.

\section{FoucAult, Biopower, AND Biopolitics}

Salter writes, "The history of the body politic is inextricably intertwined with the history of the political body." 2 This statement neatly summarizes Foucault's conception of biopolitics. ${ }^{3}$ For Foucault, the modern state has become increasingly preoccupied with the intersection of power and human biological existence. Human health started to figure into conceptions of power to become a form of power itself. Foucault asserts:

The body is also directly involved in a political field; power relations have an immediate hold upon it; they invest it, mark it, train it, torture it, force it to carry out tasks, to perform ceremonies, to emit signs. This political investment of the body is bound up, in accordance with complex reciprocal relations, with its economic use; it is largely as a force of production that the body is invested with relations of power and domination; but, on the other hand, its constitution as labor power is possible only if it is caught up in a system of subjection (in which need is also a political instrument meticulously prepared, calculated, and 
used); the body becomes a useful force only if it is both a productive body and a subjected body. ${ }^{4}$

As such, the state took a growing interest in regulating, moderating, and overseeing the health of its citizens in various, distinct realms. The state "progress[es] from a theory of sovereignty, which is 'bound up with a form of power that is exercised over the land and the produce of the land, much more so than over bodies and what they do,' toward a theory of a 'disciplinary' society that constitutes and normalizes in addition to rejecting and excluding." ${ }^{5}$ It introduces policies, procedures, and regulations that allow it to regulate and optimize life. Some have called the resulting policies and attitudes "the reign of the monogamous jogger."

Foucault subdivides the state's interest in and regulation of the body into three realms. The first and broadest is biopower, by which states acquired power over people as biological entities instead of simply as political subjects. The bodies themselves, and not just what they represent, becomes an important concern for the state. At this point, which Foucault identified as emerging in eighteenth century Europe, state politics took an active role in regulating the health and well-being of its populace. With this shift, "political power [took] over care of the biological life of the entire social body." 7 The state was no longer content to regulate defense and economics; it now saw the regulation of citizens qua humans as integral to its very existence. ${ }^{8}$ Biopower represented the extension of state power because the state now sought to implement policies specifically designed to regulate the physical well-being and health of its populace. ${ }^{9}$

The shift in the basis of a state's power opened a new realm of discipline and coercion. The state no longer needs to rely so much on its overt ability to force changes. Instead, it sought to flex its power through standardizing human existence. "Techniques to control the individual body were integrated into biopolitical techniques that sought to control the standardized multitude of bodies or the statistical 'middle-man' that represents this standardized being." 10 Governments exerted their control through instilling habits to promote the physical and moral well-being of both individuals and of society as a whole. These habits, while seemingly beneficial to individuals, promoted the state's interests and its desire to improve its security and economic wealth.

To understand the emergence of biopower, Foucault subdivided the concept into anatomo-politics and biopolitics. Anatomo-politics focuses on state efforts to make individual human bodies both more 
productive and more docile. This microlevel manifestation of biopower seeks to convince individuals to change their health-related behaviors in ways that will enrich the state and secure its power against any challengers. Anatomo-politics focuses attention on disciplining the individual body. It is "centered on the body as a machine: its disciplining, the optimization of its capabilities, the extortion of its forces, the parallel increase in its usefulness and its docility, its integration into systems of efficient and economic controls." In so doing, anatomo-politics becomes a sort of invisible power intertwined with various systems of knowledge and surveillance. This idea extends his previous work on discipline and punishment at the individual level to the realm of health. ${ }^{12}$

More relevant for the present purposes is the second dimension of biopower-biopolitics. Whereas anatomo-politics focuses at the individual level, biopolitics concerns itself with the population as a whole. It represents the attempts by governments to regulate health indicators within the entire group, focusing on areas like birth, mortality, and morbidity rates. It focuses on the size and quality of the population, reproduction rates, and on familial relations. ${ }^{13}$ To measure such population dynamics, though, the government must collect a great deal of information. This gives the government vast surveillance responsibilities. As the government collects data, it then crafts various interventions to promote its own power. ${ }^{14}$ Collecting this demographic data also gives the government powers to classify the population along the lines it sees fit. The decision to disaggregate data along some dimensions (such as race or marital status) but not others (like class) can have immense consequences for the sorts of interventions implemented and the issues that receive government attention. ${ }^{15}$ This provides a great deal of regulatory power to the state.

As originally used, Foucault's notion of biopower and biopolitics generally restricts itself to the national level. This largely makes sense, as he finds a correlation between the rise of the modern state with the rise of biopower. In recent years, though, scholars have shown that Foucault's ideas about surveillance and "panopticism" hold a great deal of relevance at the international level. Panopticism traces its intellectual origins to Jeremy Bentham. In 1785, he designed a prison that allowed guards to monitor all prisoners at any time, but the prisoners could not tell if they were being watched at any particular moment. Because the possibility of surveillance existed, Bentham believed it would encourage prisoners to behave properly and monitor their own actions. Foucault extended this idea to the broader society, arguing 
that similar self-policing structures exist throughout society. Through these structures, power functions automatically to enforce discipline on the broader society even if no one is (seemingly) exercising power in an overt fashion. Stephen Gill, for example, discusses how the neoliberal economic system and its attendant surveillance systems exercised through instruments like credit cards condition behavior and discourage people from questioning the rectitude of the system. ${ }^{16}$ Monitoring makes people compliant, Gill argues, even if they are not being overtly monitored at any given moment. It is the possibility of such monitoring that encourages such "proper" behavior.

Panoptic surveillance is generally associated with the state and frequently has negative connotations, but neither need be the case. Steele and Amoureux examine how nonstate actors like Amnesty International and Human Rights Watch (HRW) engage in panoptic surveillance for the greater good. These organizations provide an effective and efficient means for preventing human rights abuses and genocide. They "represent a lighter and more rapid form of power structures than the hegemonic power of sovereign states." 17

Further, recent events demonstrate the growing use of health surveillance at the international level. The $\mathrm{WHO}$, long considered a moribund institution, has taken an active and aggressive role in collecting and disseminating information about human cases of SARS and avian flu. UNAIDS, an organization drawing on the collective strength of a dozen UN-affiliated bodies, has established itself as the definitive repository of demographic information about the worldwide spread of HIV and AIDS. Not only can it provide aggregate numbers, but it also subdivides this data by various groups, such as women, men who have sex with men, intravenous drug users, and commercial sex workers, among others. Projects receiving funding from the Global Fund to Fight AIDS, Tuberculosis, and Malaria must not only demonstrate the utility of their planned interventions, but future funding is contingent upon adequate and continuous monitoring and evaluation throughout the project's lifecycle. Biopower even finds its way into the United Nations' Millennium Development Goals (MDGs). ${ }^{18}$ Half of the MDGs explicitly address health-related concerns, such as reducing maternal mortality, cutting the spread of HIV, and eradicating extreme hunger. The MDGs are predicated on the very notion of biopower. Advocates emphasize that one of the key advantages of the MDGs is that they provide concrete, quantifiable, and measurable targets. Thus, to know whether the world is making progress toward realizing the MDGs, the international community must engage 
in active surveillance of health indicators for nearly every country in the world. ${ }^{19}$

\section{Origins of Health Surveillance And BiOPOLITICS}

Health status has long served as a social marker. Fidler notes, "Infectious disease measures historically have served as demarcations by which 'we' protect ourselves from the diseases of 'others.' "20 We are healthy; they are diseased. As a result, we need to be protected from them so that they do not infect $u s$. Just prior to the dawning of the twentieth century, the world was gripped by a widespread bubonic plague epidemic. Government officials around the world used the fear of plague's spread by the "dirty Others" to justify discriminatory laws and essentially deny citizenship to large swaths of their populations. In San Francisco, political leaders blamed plague on the city's burgeoning Chinese population and instituted segregationist policies to provide a physical separation between the whites and the Chinese. ${ }^{21}$ Thousands of miles away, South African government officials used the same argument-that the nonwhite population was bringing plague to the city-to create "native locations" and establish sanitary corridors between the white and black population centers in Cape Town. This was the first instance of the South African government deliberately segregating racial groups, and it was explicitly justified on public health grounds. ${ }^{22}$ In both instances, government officials used health status-or, more precisely, perceived health status-as a marker of membership within the larger political community. Those deemed "sick" were excluded from participating.

Along similar lines, the spread of diseases has often been blamed on the habits or mere presence of such disfavored groups. When bubonic plague devastated Europe in the 1300s, killing roughly onethird of the continent's population, blame for the disease often fell upon Jewish populations. Some accused Jews of poisoning wells. Others believed the plague came from God's extreme anger, and they targeted Jews as the provocateurs who inspired such ire. As a result, the Jews faced persecution, forced removal from their lands, and, in some instances, murder at the hands of Christians seeking an explanation for this dreaded epidemic. ${ }^{23}$

In its earliest manifestations, biopolitics often found resonance in urban reform movements in the late nineteenth century. Reformers saw cities and towns as poor, dirty, and unhealthy. Their residents often lacked education or job opportunities. They suffered the effects 
of rampant pollution. Such unhealthy conditions impeded their ability to prosper and break out of the cycle of poverty in which they were trapped. To improve the situations of the poor, though, required more than simple medical interventions; the health of society had to improve. "People had to be made more 'healthy' and educated," writes Padovan, "air and cleanliness should prevail everywhere, cities should be rebuilt, sewers dug, fountains, schools, parks, gymnasiums, chemists, and hospitals were all required, if public health were to improve." 24 Treating individual pathologies required addressing these social pathologies. Improving the society's health became part of the government's basic function. Society had to be remade, and it was the state's responsibility to remake it. The government now had a clear interest in understanding and regulating the health of the social health, and it sought to instill proper health and hygiene habits in each individual "that would improve both the physical and moral health of each individual through public education, family involvement, and by state intervention in the field of the most common social areas of health disease." 25

Biopolitical regulation would allow the society to prosper economically and shift how it allocated its resources. "While spending to clean up the urban environment might appear to increase the sphere of government, the cleanup would actually lessen the need for bureaucracies devoted to other problems." 26 By exercising power through biopolitics, the state would reduce the need to exercise its power in other realms. This fits with emerging norms of utilitarianism. Government actions should be judged not by their costs, but by whether they improved industrial production. The failure by the state to promote the health of the social body cost the laborers who died prematurely as well as the larger community that lost out on potential profits and the expense of providing social welfare services. ${ }^{27}$

Edwin Chadwick was one of the key proponents of this belief. Chadwick was a British social reformer inspired by Jeremy Bentham's utilitarian ideas, and he served as secretary of Britain's Poor Law Commission. Writing a report on urban squalor and its effects on the British economy and moral standing in 1842, Chadwick argued that an improvement in public health would lead to a reduction in national welfare rolls. Living in poor and dirty conditions damaged moral character. It caused people to become "improvident, reckless, and intemperate, and with a habitual avidity for sensual gratifications." 28 They would "spend their earning weekly in the beer shop; associating with the worst of characters, they become the worst of laborers, resort of poaching, commit petty thefts, and add to the county rates by 
commitments and prosecutions." ${ }^{29}$ Regulating health, therefore, became a way of regulating the economy and disciplining people to live right so as not to pose a burden on society. Living a healthy life would instead allow people to contribute to society in a positive manner. Chadwick's report spelled out the case for government intervention in regulating the bodies and the health of Britons.

Some have extended biopolitics even further, tying it to the rise of fascism and eugenics. If biopolitical regulation seeks to improve the health of the societal collective, then it is not far-fetched to argue that the state has an interest in promoting certain kinds of members of this collective. Eugenic strategies could maximize the fitness of the population through incentives and compulsion to prevent certain classes of people from reproducing. ${ }^{30}$ This gave the state a direct role, in some cases, in determining who should marry. It also led to sterilization campaigns-some voluntary, some forced-aimed at members of "undesirable" groups. ${ }^{31}$ The state sought to rationalize reproduction to strengthen the society and to produce more individuals who would epitomize society's values. Science, according to the eugenicists, could provide us with the tools to identify and replicate the best qualities of the human race, and that knowledge could then be used to improve the state. ${ }^{32}$ This system entrenched a social and biological hierarchy within society, putting the weight of the state behind it.

\section{Modern Health Surveillance}

We can track much of the modern understanding of public health surveillance back to one man: Alexander D. Langmuir. Through his work with the Communicable Disease Center (CDC), Langmuir redefined public health surveillance and its role in shaping the state's policies on biopolitics.

During World War II, the U.S. Public Health Service maintained the Office of Malaria Control in War Areas (OMCWA). Its function was to control and prevent malaria among soldiers both in the United States and on the battlefield. With the war's conclusion, this office morphed into the CDC-the forerunner of today's Centers for Disease Control and Prevention. The CDC built upon the disease control and prevention experience of the OMCWA, applying its insights to a wider range of illnesses. Concurrently, the United States' military involvement on the Korean Peninsula was beginning. Fears arose among political and military leaders in the United States that Communist forces could use biological weapons against American soldiers. Chinese propaganda alleged that American military forces were using biological weapons and warned that they would respond 
in kind. ${ }^{33}$ U.S. government leaders responded by calling for the creation of an early warning system to alert military commanders of any such biological weapons attack in a timely fashion. ${ }^{34}$

Enter Alexander Langmuir. A professor of epidemiology at Johns Hopkins University, Langmuir joined the CDC in 1949 as its chief epidemiologist. His chief task in those early days was to develop the nascent organization's epidemiological capabilities so as to be useful on a practical basis. To this end, he created the Epidemic Intelligence Service (EIS). Members of the EIS commonly called "the disease detectives," received two-year postgraduate fellowships to public health personnel in applied epidemiology to link disease outbreaks with their causes and recommend treatment and prevention options. EIS officers acted as a public health early warning system, alerting officials before a disease got out of hand. ${ }^{35}$ EIS essentially put surveillance into practice and trained future generations of public health professionals to do the same.

The main innovation of the EIS was to rely upon applied epidemiology. Applied epidemiology, which Langmuir often called "shoe leather epidemiology," 36 marries epidemiological insights into policy actions to protect and improve the health of a given population. This means investigating health problems, monitoring changes in health status of individuals, and evaluating the efficacy of certain interventions. During his twenty-one years at the CDC, Langmuir placed heavy emphasis on the need for epidemiologists to go into the field, collect their own data, and see the conditions on the ground. They needed to rely heavily on and conduct their own active surveillance. Applied epidemiologists translate scientific studies into practical and effective public health programs and often play a vital role in defining health risks and their potential treatments. ${ }^{37}$ This meant a prominent role for biopolitical surveillance. The approach of the EIS is widely credited for identifying the bacterium that causes Legionnaires' disease and identifying toxic shock syndrome, though Langmuir criticized the service for its poor response to AIDS. ${ }^{38}$

This new method of operating also entailed a new definition of public health surveillance. Although previous definitions had focused on the individual and the means by which individuals spread disease through their contacts with other individuals, ${ }^{39}$ this new definition paid more attention to disease themselves and their distribution throughout the entire population. Writing in 1963, Langmuir defined this new notion of public health surveillance as

the continued watchfulness over the distribution and trends of incidence through the systematic collection, consolidation, and evaluation 
of morbidity and mortality reports and other relevant data. Intrinsic in the concept is the regular dissemination of the basic data and interpretations to all who have contributed and all others who need to know. ${ }^{40}$

This redefinition of surveillance emphasized the role of aggregate data. It focused less on individual cases and more on the emergence of statistical anomalies within populations and applying strategies to those populations. Individuals are important only insofar as they manifest a particular disease; it is the emergence and distribution of the disease itself that matters.

Shifting to a disease-centered definition of public health surveillance also means that the entire population is essentially under surveillance at all times. If the emergence of any new disease or a change in its distribution occurs at random, then operations need to be in place at all times in order to allow the surveillance mechanisms to detect these changes. They require large amounts of data in order to identify what is "normal" and what is "abnormal." It also suggests the need for a robust public health infrastructure to implement the recommendations of EIS or any other public health agency that detects some anomaly in the population's health. Sharing of epidemiological data only matters if there is someone with whom you can share.

Langmuir's redefined notion of public health surveillance continues to resonate today. Indeed, the current operating definition of surveillance used by WHO officials is essentially a condensed restatement of Langmuir's early assertion. As defined by WHA resolution WHA58.3,

Surveillance means the systematic ongoing collection, collation, and analysis of data for public health purposes and the timely dissemination of public health information for assessment and public health response as necessary. ${ }^{41}$

This definition, just like Langmuir's, pays particular attention to the need to collect aggregate data and the need to share findings with relevant parties. It also suggests an important role for national and local public health infrastructures to carry out the necessary response.

WHA58.3's definition of surveillance provides the clearest understanding of what public health surveillance is today and how most public health actors operationalize it. The WHO is the international community's leading public health agency, so its operating definitions function as default definitions for the world. In this case, a 
seemingly innocuous definition both provides hope for the strengthening of public health infrastructures worldwide and alarms those who fear the intrusion of biopolitical surveillance.

\section{Biopolitics TODAY}

Where do we see evidence of this increased emphasis on biopolitics and health surveillance today? One crucial area is in data sharing. Public health officials worldwide have called upon the international community to do a better job of collecting and sharing data. They often connect their pleas to increased globalization. "Free movement of goods and people create a need for national surveillance institutes to communicate events to each other regularly, sometimes rapidly, and to use similar surveillance components and case definitions." ${ }^{2}$ As people and goods circulate more widely and easily, fears increase that disease could inadvertently travel with them. Travelers can get to the other side of the world in less than two days. That is faster than it takes for clinical symptoms of many diseases to materialize. People could conceivably carry an illness around the world, potentially infecting hundreds or thousands, before they even begin to feel ill. Such free and easy movement, generally associated with globalization, makes the timely sharing of public health information even more imperative.

It is not enough to simply share information, though; public health officials must use the same vernacular and diagnose diseases in a similar fashion. Reintjes et al. identify the existence of different clinical definitions for diseases among the countries of the European Union as impeding the development of more robust, continent-wide public health surveillance system. They make a plea for the standardization of diseases, paralleling Foucault's arguments about biopolitical surveillance encouraging the standardization of human health and behavior. $^{43}$

One of the most concrete manifestations comes through the increased collection of statistics. Recent years have seen an increased emphasis on collecting quantitative data on mortality and morbidity rates for various diseases. UNAIDS estimates the number of people who are currently HIV-positive at 33.2 million. ${ }^{44}$ Thanks to the WHO's efforts, we have confirmed 408 human cases of avian flu, 254 of which resulted in death, as of mid-February 2009. ${ }^{45} \mathrm{WHO}$ also reports 8,096 confirmed SARS cases and 774 deaths from the same disease in 2002 and 2003. ${ }^{46}$ In the past, states may have resisted sharing this sort of data. They may have underreported cases or even denied a disease's presence within its borders to prevent looking 
weak or unable to respond. ${ }^{47}$ Today, though, states face increasing pressure to share this data, and WHO has cultivated ties with medical professionals around the world to get information that government officials may not want released. During the SARS outbreak, Chinese government officials initially denied the existence of the disease. When they acknowledged the disease's presence, they deliberately underreported the epidemic's scope. Public pressure forced the government to admit the extent of the disease, and WHO officials found the information they needed to prevent the disease from spreading even further by working outside the officially sanctioned channels of communication. ${ }^{48}$

These data go beyond raw numbers-even beyond reports by country and gender. The SARS data, for example, provide information like median age, dates of first and last cases, number of infections among health care workers, and how many cases were "imported" from another country. The AIDS data provides a similar level of detail. Some individual country reports even estimate the number of cases among particular "high-risk" groups, such as commercial sex workers, intravenous drug users, and men who have sex with men. This provides an important level of detail that could be useful for devising appropriate responses from the medical community. It also stokes the Foucauldian fears of health classification as an instrument of control. Classification and quantification, in the biopolitical sense, can be used to separate groups and deem certain groups as "highrisk" or requiring greater observation, such as the quarantining of AIDS patients in countries like Cuba.

The updated IHR factor prominently in any discussion of health surveillance and biopolitics. ${ }^{49}$ Originally adopted in 1969, these Regulations underwent massive changes at the hands of the WHA in 2005. The previous version focused largely on passive measures of disease control and notification, and it only applied to four diseases: smallpox, cholera, plague, and yellow fever. The revised version sought to implement more active control and containment activities, the requirement of more proactive international notification of disease outbreaks, and the expansion of the list of notifiable conditions.

The new IHR "aim to prevent, protect against, control and respond to the international spread of disease while avoiding unnecessary interference with international traffic and trade." Under this new framework, all member-states are required to "notify WHO of all events that may constitute a public health emergency of international concern and to respond to requests for verification of information regarding such events." ${ }^{50}$ States not only have to tell the international 
community about any disease outbreaks, but they also have to answer any questions the international community may have about diseases within their borders. The IHR also require states to develop core national public health capacities that will assist with both control and surveillance of disease outbreaks. Instead of just applying to the original four diseases, the new regulations apply to any public health event that could pose a threat to other states through its international spread and could potentially require a coordinated international response.

By upholding these new standards, states stand to gain many benefits. They have access to WHO technical assistance and support, receive support and guidance on strengthening core public health competencies, and gain access to the Global Outbreak Action and Response Network (GOARN), WHO's “ ‘one-stop shop' of global resources to help manage public health risks and emergencies of international concern." Adhering to the IHR also allows a state to consider itself a "respected partner in the international effort to maintain international public health security." 51 Thus, the IHR distinguish states as responsible members of the international community. They come with both psychic and tangible benefits. Proper health surveillance leads to respect and status within the international community.

When it comes to disease epidemics, such panopticism and biopolitical surveillance proves useful and beneficial. Epidemics are often random events, especially when new pathogens find a niche within the human population and take hold. Though it would be irrational to assume that no new pathogen would ever emerge, no one could have foretold, for instance, that SARS would emerge. Epidemics strike without warning. The very randomness makes it all the more important for states to be ready to respond effectively and collaborate with the international community at a moment's notice. Structures need to be in place ahead of time. Preparation increases the chances that a state will be able to address the epidemic's challenges in a timely manner. Just as Bentham's panopticon could watch the prisoners at any time so can an epidemic strike at any time. A state that had failed to discipline itself properly by establishing some sort of response plan could find itself in real danger. The WHO openly exhorts states to prepare for potential pandemics. Such actions will lead to "an integrated global alert and response system for epidemics and other public health emergencies based on strong national public health systems and capacity and an effective international system for coordinated response... [to] strengthen biosafety, biosecurity, and readiness." 52 
We also find evidence of increased health surveillance and biopolitics in the securitization of disease. Infectious diseases have increasingly inhabited the domain of "high" politics of national security from its more traditional realms of the "low" politics of social issues and policies. Fidler goes so far as to call international health's previous status "really low politics" because it was "considered technical, humanitarian, and non-political." ${ }^{53}$ Recent years, though, have seen a dramatic shift. In 2000, the United Nations Security Council held a special session dedicated to exploring the international security ramifications of AIDS. This was the first time ever that the international community's highest body had ever devoted a session solely to a public health issue. While some dismissed the session as political pandering for an American audience, ${ }^{54}$ this was not the only, nor the first, instance of linking public health and national security. A 1987 National Intelligence Estimate, pulling together the combined opinion of the government's various intelligence agencies, argued that the AIDS epidemic was already increasing the likelihood of instability in Africa thanks to increased tensions between states and the negative economic effects of the disease. ${ }^{55}$ A decade later, the U.S. National Intelligence Council published a report, The Global Infectious Disease Threat and Its Implications for the United States. This report explicitly linked AIDS, Ebola, tuberculosis, and other diseases with the U.S. ability to defend itself. With increased cross-border traffic and increasingly drug-resistant microbes, the authors argued, all governments around the world faced an unprecedented threat to their national survival from infectious diseases. ${ }^{56}$ A 2002 report by the same body focused specifically on the AIDS epidemics in Nigeria, Ethiopia, Russia, India, and China. These countries currently have relatively low HIV prevalence rates, but the National Intelligence Council singled them out because they (a) have growing infection rates; (b) are quite populous; and (c) are regional hegemons whose AIDS-induced instability could have dramatic effects for their regions and the world as a whole. ${ }^{57}$ The U.S. document National Strategy for Pandemic Influenza explicitly links the country's need to be prepared to its larger national and international security concerns and places a strong emphasis on surveillance. ${ }^{58}$ In 2005, prominent U.S. senators Richard Lugar of Indiana and Barack Obama of Illinois (now the U.S. president) echoed this call, putting avian flu in the same potential threat category as nuclear proliferation and rogue states. They called on the government and the international community to pay greater attention to this security threat and to "increas[e] international disease surveillance... especially in Southeast Asia." 59 In these ways, 
increased surveillance is explicitly tied with ensuring national and international security.

Efforts to include health issues under the rubric of national security are hardly uncontested, as Peterson eloquently illustrates. ${ }^{60}$ What is telling, though, is that such a debate is even occurring. Few scholars or policymakers argue for a direct link between health status and the outbreak of hostilities, but there exists a growing awareness of the indirect effects health has on national security. Price-Smith describes health as a stressor variable, exacerbating the problems faced by states with weak national security apparatuses. ${ }^{61}$ Peterson and Shellman find that rising HIV infection rates effect national social, economic, and political institutions, which in turn undermine state security systems through indirect processes. ${ }^{62}$ These efforts to securitize health and disease recast the health status of a state's citizens (as well as citizens of other states) as existential threats to the state itself; therefore, the state must be ever vigilant against health-related threats to ensure its own survival. Health, then, must move out of the relatively technocratic realm of low politics and into more survival-oriented realm of high politics.

\section{Being Watched: The Potential Perils of BiOPOLITICS}

Fears of biopolitics and objections to it largely fall into one of two camps. The first concerns states being forced to adopt inappropriate institutions or being used as international guinea pigs. The second focuses on inappropriate, often overly militarized, responses. Both of these objections suggest that the emphasis on biopolitics provides a cover for leaders to achieve other political aims under the guise of humanitarianism.

The first objection relates to the use and abuse of biopolitics by outsiders to take advantage of a situation. States have expressed concern that foreign interests use claims of bringing health to undermine state sovereignty, weaken political institutions, and subject people to medical experiments.

Part of the fear comes from how infectious disease can be used to negatively single out particular states. Countries (and individuals) feared that greater scrutiny of their infection rates could undermine their standing within the international system. They would be marked as unworthy or uncivilized, falling victim to a new "standard of civilization." 63 Fortin noted in the mid-1990s that "surveillance was believed to be society's protective response not only to the 
infectious nature of the disease, but also to what people thought to be the dangerous difference, psychological and more, that the infection symbolized between those who were, and who were not, struck by the plague." ${ }^{\prime 4}$ Haitian officials reacted with outrage when the United States identified Haitians as one of the four main risk groups for HIV in the mid-1980s. They blamed the designation for decimating the Haitian tourism industry and causing great harm to the national economy. ${ }^{65}$ Early discussions of AIDS' effects on Africa highlighted the disease's potential to reinforce an image of helplessness and underdevelopment, further marginalizing the continent within the international political economy. ${ }^{66}$ More recently, the Chinese government initially went to great lengths to cover up the extent of the SARS epidemic in 2002 and 2003 out of concern for the socioeconomic repercussions and the perceived potential for political instability. ${ }^{67}$

In all of the above examples, government officials connected disease outbreaks and the resulting international scrutiny with ostracism. They feared that other states will perceive the disease as evidence of the state's weakness and make them vulnerable to the machinations of outsiders.

On the flip side of this argument, developing a state's public health surveillance capabilities may not necessarily respond to that state's public health needs. External donors often assume that developing countries want to implement surveillance systems and simply lack the financial resources necessary to make this a reality. Calain identifies four reasons why states may resist implementing surveillance systems. First, externally financed systems may lead to redundancy and overlap. Different donors, focused on different diseases and with different agendas, may lead to confusion, unnecessary duplication of services, and the depletion of scarce human resources. Second, confusion may exist as to the purpose of collecting this data. Is it for planning and managing public health programs, or is it for identifying outbreaks? Is it for national or international officials? These may seem like unimportant distinctions, but the different purposes may provoke different responses and engender different fears about who is conducting the surveillance and for what purpose. Third, disease surveillance systems may place additional administrative burdens on public health workers and officials. If resources are limited, officials may be reluctant to orient their energies toward filing reports for national and international organizations. Finally, public health workers may see little, if any, reward for their compliance. They may not gain access to laboratory facilities, essential pharmaceuticals, or extra workers to help them 
address the disease outbreak. In other words, reporting a disease outbreak just places an additional burden on the local worker. These objections highlight the fact that disease surveillance systems may not be the highest priority for health officials in countries that are straining to provide basic health services. The international community's surveillance needs and interests may not line up with the health needs and interests of the local population. ${ }^{68}$

We can see some of these tensions playing out in Indonesia over responses to avian flu and cooperation with the international community. The Indonesian government tried to fight back against the perceived increased in biopolitical surveillance. Indonesia has experienced 141 human cases of avian flu as of mid-February 2009-the highest number for any country in the world. ${ }^{69}$ Current WHO policy asks, though does not require, states to send virus samples from each confirmed human cases to labs approved by the WHO. The labs, in turn, can use the samples in their efforts to create a commercial vaccine to combat $\mathrm{H} 5 \mathrm{Nl}$. Considering that the number of cases in Indonesia is high, WHO scientists had a clear interest in obtaining these samples. In February 2007, the Indonesian government announced it would no longer share its virus samples with WHO unless the organization promised that Indonesia that it would receive guaranteed affordable access to any resulting vaccine. ${ }^{70}$ Indonesian health officials "were angry that viruses from their country might be used to make a commercial bird flu vaccine that they themselves would never be able to afford." 71 WHO and Indonesian officials reached a compromise in late March to resume sample sharing but resumed their boycott seven months later. ${ }^{72}$ In essence, the Indonesian government objected not only to health-related surveillance, but also to the fact that they would see few, if any, of the benefits of that surveillance. They sought to reorder the balance of power between the "surveillers" and the "surveilled."

The other major concern about the increased surveillance associated with biopolitics focuses on overly militarized responses. As we redefine infectious disease as a security threat, critics have warned that governments may inappropriately rely on traditional security apparatuses to address the problem. Deudney raised a similar concern with the environment. If environmental degradation is deemed a security threat that concerns national and international stability, it may lead political leaders to call on military forces to confront the threat. Militaries may be useful for traditional threats, but they may be poorly equipped to respond to environmental degradation or infectious disease. ${ }^{73}$ 
Militaries can and do play a role in biopolitical surveillance. Some of this is concentrated on the members of the armed forces. Military commanders have an obvious interest in ensuring that their forces are healthy and able to respond to situations as they arise. The military often creates its own parallel public health infrastructure specifically for its members. Like any other public health system, the military seeks to monitor, treat, and prevent illnesses. However, those same capabilities can be extended to monitor civilian populations. Militaries may have laboratory and diagnostic capabilities beyond those of traditional public health organizations. They may also have the logistical and organizational capabilities to facilitate rapid deployment in epidemic regions and the communication technologies to communicate with WHO officials in a timely manner. ${ }^{74}$ Indeed, in developing countries, the military may be the only organization with these capabilities. Such an extension of military capabilities into decidedly nonmilitary realms raises fears of the militarization of society. Chretien et al. suggest that some governments have essentially turned the provision of public health services and disease surveillance over to military forces "by providing health services for civilians in remote areas and reporting military surveillance data to the ministry of health." 75 This extends the role of the military into a more prominent place within the domestic arena.

The connections between military forces and public health are not limited to developing countries. Within the United States, much of the global infectious disease surveillance system is linked to the Department of Defense (DoD). In the 1990s, the U.S. government established the Global Emerging Infectious Surveillance and Response System (GEIS). The system set up mobile laboratories that could quickly respond to disease outbreaks around the world. Interestingly, GEIS comes under the administrative aegis of the DoD, not one of the diplomatic or humanitarian bureaucracies in the government. "Their location in the DoD, as opposed to the United States Agency for International Development (USAID) or Center for Disease Control (CDC) demonstrates how seriously the United States views the response to infectious disease as a key national security strategy."76 Surveillance becomes inextricably linked with the military and the deployment of military personnel in foreign countries. Fears arise that this could cloud the state's response, leading to rely too heavily on military, as opposed to health, means. It also could potentially place the military in a strong position for ensuring and regulating the population's health.

Pandemic influenza preparations have further stoked fears about the links between biopolitical surveillance and the role of the military. 
In 2005, U.S. President Bush released the document National Strategy for Pandemic Influenza. The document focuses on preparedness, surveillance, and containment. This strategy calls upon government officials at the local, state, and federal government to develop mitigation strategies, build greater lines of communication between officials, and collaborate with international partners. To contain an outbreak, the strategy acknowledges that military capabilities may be used domestically to provide additional medical facilities and to engage in "infrastructure-sustainment activities." 77 Bush expanded upon the military's potential role during a press conference. He remarked:

If we had an outbreak somewhere in the United States, do we not then quarantine that part of the country, and how do you then enforce a quarantine? When-it's one thing to shut down airplanes; it's another thing to prevent people from coming in to get exposed to the avian flu. And who best to be able to effect a quarantine? One option is the use of a military that's able to plan and move. ${ }^{78}$

Some have seized upon this potential role for the military as proof that governments are using the threat of an infectious disease outbreak to introduce an overly militaristic response that could border on martial law. The United States' pandemic influenza program specifically carves out a special role for the military in providing medical services, enforcing quarantines, and ensuring continuity of government and economy. Some critics of this program have argued that it essentially allows for the declaration of martial law. ${ }^{79}$ Greger argues that using the military to institute some sort of quarantine, as he suggests the National Strategy for Pandemic Influenza allows, would serve only to increase stigmatization and discrimination. This would drive people further away from medical attention and exacerbate an epidemic. $^{80}$ Irwin Redlener, the dean of Columbia University's Mailman School of Public Health, called the militarized aspect of the government's response "extraordinarily draconian" and equated it with martial law. ${ }^{81}$

More bombastically, Michael Osterholm, an advisor to the U.S. government on its pandemic flu preparations, paints the following doomsday scenario:

Border security would be made a priority, especially to protect potential supplies of pandemic-specific vaccines from nearby desperate countries. Military leaders would have to develop strategies to defend the 
country and also protect against domestic insurgency with armed forces that would likely be compromised by the disease. ${ }^{82}$

He goes on to discuss the fallout from the government's failure to properly securitize pandemic influenza:

Someday, after the next pandemic has come and gone, a commission much like the 9/11 Commission will be charged with determining how well government, business, and public health leaders prepared the world for the catastrophe when they had clear warning. What will be the verdict? ${ }^{83}$

Osterholm's prognostication envisions widespread looting and the need for roaming militias to ensure access to drug supplies as he envisions millions of people dying. He speaks strongly about the need to protect our borders to prevent people from coming to the United States to get America's drugs. This also suggests that pharmaceutical manufacturing capabilities may become a national security issue, as could access to antiretroviral drugs in developing countries. Garrett notes that pharmaceutical patent protections are stoking anti-Western sentiments in some countries, threatening to create greater problems. ${ }^{84}$

These concerns about the role of the military in responding to a disease outbreak get to the very heart of surveillance. Fears have arisen about the potential for overt coercion going hand in hand with increased government surveillance in public health. Government officials have linked increasing adherence with universal standards embodied within increased health surveillance with a loss of sovereignty, attempts to weaken the state, and domination by Western states.

\section{Promise of Biopolitics}

The specter of increased biopolitical surveillance can certainly induce fear, but is biopolitics necessarily a dangerous concept within the international community? Could biopolitical surveillance benefit states and international health? There is reason to believe it could. As public health becomes an increasingly important issue within the international political realm, we see greater resources devoted to it. Countries express greater concern about the need to address health problems in other places. Though they may do it for selfish reasons (like preventing instability or the disease's spread to its own territory), states have shown a greater willingness to devote energies and resources to preserving the public's health-and the world benefits from this. 
Surveillance can lead to greater attention to problems that would have gone unnoticed in earlier times. U.S. Surgeon General David Satcher addressed the role of surveillance in public health directly in 2001, noting, "In public health, we can't do anything without surveillance...that's where public health begins." ${ }^{85}$ Exploring how biopolitical surveillance can lead to greater attention and greater resources for improved international health can demonstrate how biopolitics need not necessarily undermine the international system.

While Foucault emphasizes the connections between state power and biological existence, it bears emphasizing that biopower directly encouraged many of the sanitary and health reforms that lengthened life spans and improved living conditions for millions of Europeans. Governments may have seen improved public health as a means for reducing the poor's financial burden on the state, but this desire allowed for the extension of sewer services, addition of health clinics, and improvement in general sanitation. These services and advantages had long been available only to the moneyed elites within society. ${ }^{86}$ Public health reforms that accompanied the growth of biopolitical surveillance brought these to the masses.

These reforms were not inconsequential. Biopolitical surveillance allowed health problems like rampant tuberculosis in the late $1800 \mathrm{~s}$ to enter the public consciousness. As the state came to understand the full extent of the problem, it devised interventions that directly contributed to reducing the rates of tuberculosis and improving the conditions that fostered the disease in the first place. Improvements in nutrition and economic standing are widely believed to have helped decrease tuberculosis mortality rates in the United Kingdom from the eighteenth through the early twentieth centuries. ${ }^{87}$ These improvements occurred prior to the development and deployment of widespread medical interventions. Effective antibiotics did not yet exist, and few could afford the treatments that were available. Instead, public health improvements, brought on through the collection and dissemination of data on rates of tuberculosis, lengthened life spans. Biopolitical surveillance directly contributed to improving the lives of citizens. It was not simply a tool of domination.

Biopolitics and its promotion of particular behaviors benefitted the life spans and general health in other ways, too. Hygiene improvements, such as encouraging breastfeeding for infants, promoting handwashing, and advising mothers to boil milk before serving it, reduced morbidity and mortality rates of infectious diseases. ${ }^{88}$ Campaigns to encourage better hygiene were often connected to broader efforts to promote the education of women, as women's 
education levels correlated with infant and child health status. ${ }^{89}$ Promoting better health behaviors thus had the positive externality of promoting and encouraging widespread women's education.

More large-scale, state-directed public health improvements, inspired by the collection of biopolitical data, played significant roles in decreasing morbidity and mortality from infectious diseases. Governments implemented programs to collect refuse, provide clean water through public works programs, inspect meat, and pasteurize milk. ${ }^{90}$ Cutler and Miller, focusing specifically on the role of clean water technologies in American cities, found that these technologies reduced mortality by 13 percent between 1900 and 1936, accounting for 43 percent of the total decline in mortality during this period. The effects were even more striking for infants and children, with clean water technologies leading to mortality declines of 62 and 81 percent, respectively. Such improvements almost completely eradicated typhoid and reduced rates of meningitis, pneumonia, tuberculosis, and diphtheria in major American cities in the first half of the twentieth century. ${ }^{91}$

These improvements did not emerge out of a sense of altruism among municipal leaders. Instead, they followed the collection and dissemination of biopolitical data. By keeping an eye on the health and welfare of the general population governments were motivated to take an active role in trying to improve the lives of city dwellers-rich and poor, young and old. Further, while some may fear the increasing role of the military in biopolitical surveillance and public health in general, the reality is that the military may be the only institution with the capabilities to do this. With weakened public health systems in many states, the military alone may possess the infrastructure and personnel necessary to effectively conduct surveillance and implement policies to prevent the spread of infectious diseases.

The increased emphasis on biopolitical surveillance has encouraged states to keep an eye on the health situations in other countries. This is of vital importance if the international community endeavors to stop disease epidemics before they get too much of a foothold or to eradicate diseases. Morse lays the argument out plainly: "The key to control of any pandemic is early identification and rapid response. This must begin with effective early warning." ${ }^{22}$ The international community cannot hope to respond to a health situation if it does not know about it. To achieve the early identification of a disease, surveillance systems must already be in place and functioning. Proactive, effective surveillance allows international officials to arrest the spread of a disease early. Bell, though a critic of biopolitical surveillance, acknowledges that such surveillance "is intended to detect, regulate, 
and perhaps eliminate corrupting factors that threaten the security of the population." 93

With greater surveillance has come greater attention to health in general. The United Nations Security Council's special session devoted to AIDS in 2000 is just one sign of the increased attention the international community is paying to health concerns. Witness the emergence of both UNAIDS and the Global Fund to Fight AIDS, Tuberculosis, and Malaria. International financial institutions like the World Bank and the International Monetary Fund have moved to place protecting and promoting the health of local populations as central to their organizational missions. The MDGs emphasize the need for the international community to draw on its collective resources to protect the health of all. The WHO, long considered a relatively dormant international organization, has been reinvigorated in recent years as a central repository and disseminator of information. It is now on the front lines of international efforts to arrest disease epidemics as soon as they emerge and a focal point for scientific efforts to identify and treat newly emerging infectious diseases. Even nongovernmental actors have also started to play a central role in providing public health surveillance and promoting disease control programs. The efforts of the Carter Center, for example, have called attention to diseases that have plagued developing countries, putting them on the international agenda. Thanks to its efforts, dracunculiasis is on track to be the first disease completely eliminated from the planet since smallpox's successful eradication. ${ }^{94}$ It was only through tracking cases of the disease and publicizing their findings that the Carter Center could marshal the support and resources necessary for such a massive undertaking.

These efforts have helped to redefine how states see their obligations to one another. Health is no longer a matter of national politics; it is now a matter of international politics. In all of these efforts, outside actors are increasingly collecting statistics and monitoring the health policy decisions being made by other states. Governments and individuals face more health surveillance from a larger array of actors, but it is through this greater surveillance that the international community has come to recognize the interdependent nature of global health. It is through surveillance and the recognition that some countries lack the resources to address their pressing health needs on their own that other members of the international community have started to contribute to these efforts.

For these outside actors to craft effective interventions and be of real assistance, they must engage in some form of monitoring. They need to know the realities of the situation on the ground. They need 
to understand what sorts of programs have been tried in the past or are currently being implemented. They need to analyze the effectiveness of their programs. All these efforts require ongoing surveillance. Critics suggest that a state will only agree to work through these international health efforts as long as they continue to benefit that government, ${ }^{95}$ but such criticism recognizes that states do see some benefit, at least for the current moment, in engaging in surveillance and allowing others to watch them.

With the greater attention paid to international health, we have witnessed a great increase in the resources devoted to addressing the issue. This, too, has only come about through increased surveillance. Government leaders explicitly link their calls for financial outlays for international health with staggering statistics. Governments around the world devoted $\$ 14$ billion for health issues in the developing world in 2004-a substantial increase over four years and that too at a time when governments faced increasing demands on their overseas development assistance budgets. ${ }^{96}$ In 2003, President George W. Bush unveiled his President's Emergency Plan for AIDS Relief (PEPFAR). It provided US\$15 billion, spread over five years, to prevent and treat AIDS around the world. Over the course of the program, it has provided services to prevent mother-to-child HIV transmission during 10 million pregnancies, made antiretroviral drugs available to nearly 1.5 million people, and offered care to 6.6 million people affected by AIDS. ${ }^{97}$ In 2007, as PEPFAR was nearing the end of its original timeframe, Bush called on the U.S. Congress to reauthorize the program for another five years-but to double the funding to $\$ 30$ billion. $^{98}$ The initial PEPFAR outlays were the largest amount of money ever given by a single country to address any health issue. A pledge of this size only came about because of our understanding of the nature of the AIDS pandemic, who it has affected, and how its unabated spread could have detrimental political and economic consequences.

These resources do not come from national governments alone. The Bill and Melinda Gates Foundation, the world's wealthiest philanthropic organization, has made global health one of its core concerns and has contributed over $\$ 3$ billion in efforts to combat malaria, AIDS, and other diseases. ${ }^{99}$ In a unique partnership of public and private funds, the Global Fund to Fight AIDS, Tuberculosis, and Malaria raised $\$ 9.7$ billion in pledges in 2007 to fund its worldwide efforts through 2010. ${ }^{100}$ The Product (RED) campaign has raised over \$100 million for AIDS relief in Africa, and funnels its contributions entirely through the Global Fund. Again, these organizations are able and willing to devote such funds only because they can 
generate the information to demonstrate the need and usefulness of these efforts. This information comes through the same potentially intrusive surveillance techniques that have given some pause.

Surveillance also introduces a level of accountability. No external force can require any state to ratify the IHR or work with international health efforts like UNAIDS, the Global Fund, or the Cater Center's efforts to eradicate dracunculiasis. Further, these programs lack strong enforcement capabilities to require compliance or impose punishment. They instead rely upon a combination of persuasion, shame, and norm internalization to encourage compliance and agreement. In such a situation, surveillance provides an avenue for monitoring compliance in a way that benefits the citizens of a given country. For example, UNAIDS strongly encourages states to implement programs that respect the human rights of people with HIV/ AIDS and to recognize the connections between a lack of human rights and vulnerability to HIV infection. ${ }^{101}$. Through surveillance, the international community can ensure that a country is doing so. It can also bring attention to any deficiencies in integrating human rights into an HIV/AIDS policy. This is not to say that there is only one right way to combine human rights and HIV. It does send a signal, though, that political leaders must be aware that disjunctures between rhetoric and policy may lead to international criticism and punitive sanctioning. Such oversight benefits not only the citizens of a given country, but also the entire international community.

\section{ConCLUSION}

With increased attention to health within the international community has come increased surveillance. This has raised fears among some that this surveillance could redefine biopolitical citizenship and become a new "standard of civilization." Others have called this an advance for recognizing the interdependence of global health. Both of these perspectives are at work within the international community. International cooperation to advance global health is a positive move, but it is important that such moves are not overshadowed by fears of political exploitation.

Cooperation is also the key to providing global public goods, but it can be difficult to achieve. All may agree that something would be beneficial, but that does not mean they all agree about the best way to provide it or who should pay for it. Chapter 2 delves into the issues surrounding global public goods-what they are, how they are provided, and how they relate to issues of health and disease. 